\title{
Carbon C 14-TAK-659
}

National Cancer Institute

\section{Source}

National Cancer Institute. Carbon C 14-TAK-659. NCI Thesaurus. Code C155968.

A radioconjug ate composed of TAK-659, an orally bioavailable selective inhibitor of the non-receptor tyrosine kinase (RTK) spleen tyrosine kinase (Syk), labeled with the radioisotope carbon C 14, with potential use for evaluating the pharmacokinetic profile of TAK-659. Upon administration of carbon C 14 TAK-659, TAK-659 targets, binds to and inhibits Syk. Labeling of TAK-659 with the radioactive tracer carbon C 14 permits the evaluation of this agent's pharmacokinetic profile, including its absorption, distribution, metabolism, and excretion (ADME). Syk, a B-cell receptor (BCR)-associated non-receptor tyrosine kinase that mediates B-cell activation, chemotaxis, adhesion and proliferation, is expressed in hematopoietic tissues and is often overexpressed in hematopoietic malignancies. 